\title{
A Study on the Application of Input Hypothesis in English Teaching of Junior High School
}

\author{
Sun Ying \\ Faculty of Teacher Education, Nanjing Normal University, Nanjing, China
}

Email address:

1105359204@qq.com

To cite this article:

Sun Ying. A Study on the Application of Input Hypothesis in English Teaching of Junior High School. International Journal of Language and Linguistics. Vol. 7, No. 6, 2019, pp. 364-367. doi: 10.11648/j.ijl1.20190706.26

Received: December 3, 2019; Accepted: December 16, 2019; Published: December 25, 2019

\begin{abstract}
Since Input Hypothesis was proposed, it has attracted the attention of domestic and foreign linguists. However, Input Hypothesis is still a "virgin land" in the teaching practices of primary and high schools. This paper aims to investigate the teaching of junior high school English so as to find out the applications of Input Hypothesis in junior high school English teaching and then propose a series of strategies that can be applied in junior high school English classes in accordance with the four principles of Input Hypothesis. The study was carried out in seventh grade of a junior high school. The researchers observed the English lessons of two classes in seventh grade for three months, analyzed the teaching plans and interviewed the teacher of the two classes. This paper found out that many teaching strategies that the teacher used are theoretically related to Input Hypothesis. However, the teacher has never learned about this theory. In order to bridge the gap between Input Hypothesis and English teaching in junior high school, this paper explained four principles of this hypothesis and put forward some possible strategies. This paper hopes to make contributions to the application of linguistic theories in English teaching og junior high school and urge teachers to equip themselves with these theories.
\end{abstract}

Keywords: Input Hypothesis, Junior High School English, Input

\section{Introduction}

In the field of language teaching, there has always been a gap between linguists and teachers. There is also one between Input Hypothesis and teaching practices. Since its publication, Input Hypothesis has made notable contributions to SLA study for its emphasis on a comprehensible, sufficient and suitable input. Scholars at home and abroad have made systematic theoretical analyses of the hypothesis, but teachers know little about this theory although they have wielded several instructional strategies which are related to Input Hypothesis. Aiming at bridging the gap between Input Hypothesis and teaching practices, this paper, first of all, studies the practical instructional strategies adopted by English teachers in junior high school and then analyzes several possible instructional strategies which are consistent with these principles.

\section{The Application of "Comprehensibility" Principle of Input Hypothesis}

Comprehensibility is a fundamental and necessary requirement in language acquisition and learning. Krashen pointed out that comprehensibility amounts to the claim that when the acquirer does not understand the message, there will be no acquisition [1].

\subsection{The Measures Taken by Junior High School Teachers to Enhance "Comprehensibility"}

\subsubsection{Provide Learning Materials that Are Based on Students' Previous Knowledge and Are Familiar to Them}

In the second volume of the PEP edition textbooks for seventh grade, the topic of Unit 5 is "animals in a zoo". At the beginning of the instruction of Section B, the teacher asked the students to listen to a conversation and circle the description 
words they hear. After studying Section A of Unit 5, students have learned some animal words and grasped the sentence patterns in the conversation. The listening dialogue is expanded on the basis of the already-learned patterns despite longer sentences and more expressions. So it is not difficult for the students to understand the dialogue.

\subsubsection{Adjust the Speaker's Language}

The teacher and the interlocutors in listening materials, have some similar characteristics that are consistent with "Comprehensibility" principle. First of all, they speak in a relatively low speed and with clear articulation. Secondly, their speeches are characterized with syntactic simplification and repetition. In addition, they seldom use expressions or sentence structures that are far beyond students' current competence. All the three methods succeed in providing a comprehensible input.

\subsubsection{Give Appropriate Instructions in Chinese}

Almost in every class, the teacher speaks some Chinese to aid comprehension in certain context. And the frequency of using Chinese depends on the complexity of the teaching point and how much students have understood.

\subsubsection{Make Full Use of Multimedia in Class}

The teacher increases the comprehensibility of input by the help of PowerPoint mainly in the following two ways. On the one hand, PowerPoint provides the teacher with the opportunity to use more pictures and videos, which is an effective way to aid comprehension. The author found that the teacher took full advantage of numerous picture. On the other hand, the teacher makes full use of PowerPoint to guide students instead of inculcating them with screens of sentences. there is one in the teaching of Unit 5. The passage in $2 b$ is about elephants in Thailand. In the first class of this part, it was taught to students with the procedures of PWP. So, in the second class, the teacher asked the students to read each paragraph and fill in the blanks.

\subsection{Possible Measures to Enhance "Comprehensibility" in Class}

Krashen provided two general ways in which teachers can aid comprehension, linguistic and non-linguistic [1]. Adjustments in linguistic aspects are fundamental in language classroom. Hatch summarized the following methods of linguistic adjustments. First of all, a slower rate and clearer articulation while teaching allow more processing time for the learners, thus enhancing understanding. Secondly, simplification of words and syntax can also help the learner to comprehend the input. Thirdly, Hatch suggested that teachers can use more vocabularies that are familiar to the learners, less slang and fewer idioms to aid comprehension [2]. Fang Bin also mentioned the above methods to enhance comprehensibility in teaching English listening. In listening teaching, the length, playing pace and speaking rate of listening materials can be changed by using online applications [3]. Besides the methods mentioned above, there is a very simple but effective way to enhance understanding linguistically which is called comprehension checking. In addition, the teacher's linguistic demonstration achieves better results in aiding comprehension than many times of instructions. Besides linguistic ways to aid comprehension, non-linguistic means deserve language teachers' recognition in encouraging comprehension. Intuitional teaching aid is the most effective and the most frequently used way among non-linguistic measures to enhance understanding. It includes the use of objects, models, pictures, graphs and so on. With the development of science and technology, there emerges quite a few dynamic non-linguistic means to aid comprehension among which audio and video are the most beneficial ones. When applying intuitional teaching aid, language teachers are supposed to have better understandings towards the learner's current knowledge of the world because it is apparent that "Harry Potter" is not a suitable video for an elementary learner. And the final non-linguistic method, the body language of teachers, is often accompanied with the above linguistic measures.

\section{The Application of "Relevance and Interest" Principle of Input Hypothesis}

As Krashen said in his book, the best input is so interesting and relevant that the acquirer may even "forget" that the message is encoded in a foreign language [1]. And the acquisition process will be accomplished only when language input is turned into language intake. And the learner's affective factors, such as learning motivation, confidence and attitudes, block this process. The more interesting and relevant language input is; the higher learning motivation will be. Then higher motivation will weaken the effects of affective filter barrier.

\subsection{The Measures Taken by Junior High School Teachers to Enhance "Relevance and Interest"}

\subsubsection{Make Full Use of Various Pictures}

Unit 4 mainly talks about different kinds of rules. When explaining what the school rules are, the teacher made full use of pictures, such as pictures of students eating in the classroom, pictures of students fighting with each other and pictures of students listening to music in class. When talking about different regulations or rules, words may increase the sense of refinement, while pictures can arouse the students' intentions and enhance "Interest".

\subsubsection{Provide Students with Opportunities to Express Their Own Ideas}

After discussing a variety of school rules, the teacher invited students to make up rules for their dream school. This is an effective way to enhance "Interest" and it is closely connected with the students' real life. In reality, the students are asked to conform to numerous school rules, they dream of making up school rules by themselves. So this activity succeeds in realizing the students' dreams and giving the students' opportunities to express their own ideas about school 
rules.

\subsubsection{Carry Out Role-play Activities}

The teacher makes full use of role-play games in every unit. But this game fails in making the learning more interesting because of the mechanical form that the teacher took when organizing this game. The fixed dialogue has no difference with mechanical exercises. Although two students play different roles in this conversation, the students have no choice but to recite it completely. They have no opportunities to think about what to say and how to answer the other interlocutor's questions.

\subsection{Possible Measures to Enhance "Relevance and Interest" in Class}

Zhang Qian pointed out that teachers need to use more diversified teaching methods to encourage the "Interest", keep the student's interest in learning forever [4]. The following possible measures that haven't been applied to practical teaching practices deserve teachers' recognition. We can divide all the possible measures into two categories for the time being.

First of all, we can find out that different types of games are very effective to motivate the students and make the class more interesting when putting the students' age and characteristics into consideration. Secondly, the teacher should prepare topic-relevant materials for the students. And finally, the teacher should create opportunities for students to express their own ideas as many as possible. If the teacher succeeds in making the topic interesting but fails in encouraging idea-expressing, the students will lose interest in the topic sooner or later.

The relevance mentioned has two kinds of meanings. First of all, the learning points should be relevant to what have been grasped by the students. The teacher should present new knowledge on the basis of prior knowledge. Secondly, the relevance means that there are connections between the learning points and the students' real life. With an immature mentality, there is no doubt that the students in junior high school care more about things relevant to their life.

\section{The Application of "Not Grammatically Sequenced" Principle of Input Hypothesis}

Krashen strongly opposes to sequence each lesson and focus on one structure. He claims that when input is comprehensible, when meaning is successfully negotiated, $\mathrm{i}+1$ will be present automatically in most cases [1].

\subsection{The Measures Taken by Junior High School Teachers to Achieve "Not Grammatically Sequenced"}

\subsubsection{Do Not Divide Units by Grammar Points}

The junior high school in Jinan use the PEP edition textbooks in which the teaching contents of 12 units are arranged in different topics and functions. And each unit contains far more than one structure. For example, in unit 5 , the topic is "animals in a zoo". After the study of this unit, the students can learn how to describe animals and express preferences.

\subsubsection{Adopt New Passage Teaching Methods}

In the process of analyzing a passage, the teacher abandons the traditional word-sentence-passage teaching method. Instead, she guides the students to taste the unique structure of the passage. And by analyzing the main idea and structure of the passage, the learning of words and expressions are accomplished naturally.

\subsection{Possible Measures to Achieve "Not Grammatically Sequenced" in Class}

In order to achieve "Not Grammatically Sequenced", we must get rid of all the flaws of teaching in such a "finely-tuned sequence". On the one hand, the teacher should not present only one grammar point in one class. And the previous points should also be mentioned in later teaching. On the other hand, the teaching of each lesson should get rid of the procedure of words-sentences-passage. The teaching process of a lesson should be in accordance with the author's writing main line.

\section{The Application of "Sufficient Quantity" Principle of Input Hypothesis}

Krashen believes that a large quantity of input is the basic requirement of language acquisition. The acquisition of a language can be achieved only when a large amount of input free of modification is provided in class and out of class. The acquisition of a language can be achieved only when a large amount of input free of modification is provided in class and out of class.

\subsection{The Measures Taken by Junior High School Teachers to Enhance "Sufficient Quantity"}

\subsubsection{Recommend Extracurricular Books to Students}

The teacher often recommends some extracurricular books to the students. For example, in the study of Unit 6 , at the beginning of the class, the teacher uploaded the electronic version of a book, Diary of Wimpy Kid, to the online learning space of the students and gave an outline of the book. By recommending such qualified reading materials, the teacher succeeded in providing a large amount of input outside the classroom.

\subsubsection{Present the same Input in Different Ways.}

When learning the passages in every unit, there are quite a few practices applied to strengthen the input. For example, when learning the same passage, the teacher uses question-answering, blank-filling, mind-mapping and retelling to ensure a sufficient quantity. It is impossible for the students to grasp a passage by only one input method or activity. 


\subsection{Possible Measures to Enhance "Sufficient Quantity" in Class}

This paper mainly provides four measures to enhance "Sufficient Quantity". First of all, teaching in class should be task-based and the tasks should be designed in different forms. Because under different tasks, the brain will intake different amount of input even if there is the same type of input. Secondly, the input should not be restricted to the textbook. The teacher should look for input through various channels. In addition, the students need the teacher to encourage and supervise them so that they can acquire sufficient input outside the classroom. And finally, there still exists a hot potato. And Krashen asked this question, "How much low filter/comprehensible input is necessary for students to acquire enough competence in the second language, so that they can use the informal environment to continue improving [1]?" At present, we cannot give a specific quantity, but the teacher can tell whether the input is sufficient or not through the students' feedback.

\section{Conclusion}

This paper carries out a case study of applying Input Hypothesis to junior high school English teaching. And the case study was conducted in the ways of teacher interview and classroom observation and recording. The study shows that the teacher did use quite a few measures in her teaching to enhance "Comprehensibility", "Relevance and Interest" "Not Grammatically Sequenced" and "Sufficient Quantity", which is the application of Input Hypothesis in junior high school English teaching. However, the teacher herself knows little about Input Hypothesis and has no idea that the measures she used in class have connections with it. So this paper helps the teacher to form a preliminary understanding towards this theory and provides more possible measures in accordance with the four principles to improve junior high school English teaching quality based on previous studies. And it also lays a foundation for junior high school teachers to fully apply Input Hypothesis to their teaching practices.

However, there still exist quite a few limitations in the study. Because of time restriction, the case study only continued about two months and included the teaching practices of three units of the seventh grade. Therefore, the result may have slight deviation with the practical application. future study can aim at verifying the application of Input Hypothesis in junior high school English teaching through empirical study.

\section{Acknowledgements}

First, I would like to express my gratitude to my supervisor, Professor Zhang Zhiyi. He gave me a lot of suggestions in choosing the topic, designing the structure of the paper and helped me to modify the paper. Secondly, my genuine thankfulness is given to the teacher and students in the junior high school. Finally, I want to thank my roommates for helping me find out the grammar and format mistakes.

\section{References}

[1] Krashen, S. Principles and Practice in Second Language Acquisition [M]. Pergamon Press, 1981.

[2] Hatch, E. Studies in Second Language Acquisition 2 [M]. Apply with Caution, 1979.

[3] Fang Bin. A Krashen-Input-Hypothesis Approach to the Teaching Strategies of English Listening in Junior Middle School [D]. Shanghai: Shanghai Normal University, 2017.

[4] Zhang Qian. The Application of Krashen's SLA Theory to Junior High School English Teaching [D]. Henan Province: Xinyang Normal University, 2018.

[5] Long, M. H. Input and Second Language Acquisition Theory [M]. Longman, 1985.

[6] Swain, M. Communicative Competence Some roles of Comprehensible Input and Comprehensible Output in its Development [M]. Rowley: Newbury House, 1985.

[7] White, L. (1987). Against comprehensible input: the input hypothesis and the development of second language competence [J]. Applied Linguistics 8(2): 95-110.

[8] Ellis, R. The Study of Second Language Acquisition [M]. Oxford: Oxford University, 1994.

[9] Wang Qing. A Course in English Language Teaching [M]. Beijing: Higher Education Press, 2006.

[10] Liu Bing. The Research of the Application of Input Hypothesis Theory to English Reading Teaching in Senior High School [D]. Chongqing: Chong Qing Normal University, 2014.

[11] Wang Dawei. A New Theory of "Input" [J]. Foreign Language World, 1997, (4): 44-49.

[12] Wang Xiaoning. Krashen's Acquisition/ Learning Hypothesis and Foreign Language Teaching. Foreign Language World [J]. 2001, 1:28-31.

[13] Ye Lehong. On Hierarchical Reading Teaching in Senior High School Based on Krashen's Input Hypothesis [D]. Jiangsu Province: Nanjing Normal University, 2018.

[14] Zhou Daisong. Research on the Application of Krashen's Language Input Hypothesis Theory in English Teaching for Low Level English Students in Junior Middle School [D]. Hubei Province: Central China Normal University, 2008.

[15] Jiang Zukang. The Study of Second Language Acquisition [M]. Beijing: Foreign Language Teaching and Research Press, 1999.

[16] Luo Lisheng; Li Zinan; Ge Lan. The Input Hypothesis by Krashen and Foreign Languages Teaching [J]. Journal of Tsinghua University (Philosophy and Social Sciences), 2001, 4: 71-74. 